\title{
An Empirical Study of the Influencing Factors of the Agricultural Service Supply of Cooperatives from the Perspective of Industrial Chain
}

\author{
Yang Fawen ${ }^{1,2}$ Yang Cheng ${ }^{1,2^{*}}$ \\ ${ }^{1}$ Sichuan Police Academy of Science, Chengdu, 610200, China. \\ ${ }^{2}$ Sichuan Police College, Luzhou City of Sichuan, 646000, China.
}

\begin{abstract}
The study is based on 162 Agricultural Cooperatives in Zhejiang Province. On the basis of literature, this paper analyzes the service situation of agricultural production cooperatives, including production, processing and financing. The influencing factors are discussed theoretically and tested empirically. The study concluded that most cooperatives provide pre-and post-production supply services to participating members, as well as financing services. In addition, in order to strengthen human resources, the leaders of each cooperative are encouraged and the service awareness of the agricultural industrial chain of the cooperative is enhanced; the membership is expanded to facilitate agricultural production and the provision of financing services by the cooperative. At the same time, the increase in post-natal strength provides a positive impact on cooperatives and optimizes the overall market environment for cooperatives. Of course, the agricultural industrial chain services provided by cooperatives are also affected by the variety of products.
\end{abstract}

\section{INTRODUCTION}

At present, with the development of China's economy, the process of China's market and agricultural modernization, the degree of specialization of production and management for farmers has gradually increased, but also the awareness of socialized services for agriculture has been growing. Regardless of the various forms of development, the purpose of the farmers' professional cooperative organization is always to serve its members.

\subsection{A General Definition of Farmer's Professional Cooperative Organization}

The organizational basis of farmers' strong identity, and the unique organizational advantages such as the membership system that integrates owners, promoters and users, it will become an important force in improving the agricultural socialized service system. In 2013, the No. 1 document of the Central Committee pointed out that "to build modern agriculture with Chinese characteristics, we must establish a perfect agricultural socialized service system". 2014-2016 years of the central document proposed continuous support and guide the farmers cooperatives expand service areas. With the development of agricultural cooperatives and the rapid increase in the number of services, has become the agricultural service cooperatives provide the largest contributor to .However, the current part of farmer cooperatives are still operating without norms, financing difficulties, the contents of a single service the lack of talent, and other outstanding issues, which will hinder the cooperative play services in the whole industrial chain of agriculture,[1] and make it impossible to grow. Therefore, in-depth study of factors of cooperative agricultural industry chain service supply and its influence on the promotion of the Cooperatives are better and faster to develop and push forward the process of agricultural modernization.

\subsection{Literature Review}

At the present stage, the academic circles have done many researches on the service function and its influencing factors of Chinese farmers' cooperative economic organizations in the agricultural industry chain and have made relatively fruitful results.

For example, Huang Jilun has studied the service function of cooperative economic organizations of farmers and its influencing factors. Huang Zuhui and Gao She-ling have constructed an analytical framework for the degree of realization of cooperative service functions. Zhong Zhen and Cheng Yao Yao used the case study method to study the agricultural service function of the dairy farmers cooperative. Mao Fei empirically analyzed the cooperative financing service supply and its application. Huang Feng and Yang Dan empirically studied the impact of cooperative internal governance on their agricultural service capacity. There

*Corresponding author. Email: ycxq520@sina.com. 
has been a lack of service to the agricultural industrial chain of farmers' cooperatives. On the basis of the existing research, this paper will analyze theoretically the influencing factors of service supply in cooperative agricultural industrial chain. Then, based on 162 farmers' cooperative data in Zhejiang province, the paper empirically analyzes the supply of cooperative services and its main influencing factors.

\section{BACKGROUND}

\subsection{Theoretical Analysis}

Cooperatives, like enterprises, are a legal fiction, balanced by complex processes within the framework of this contractual relationship by people with different goals (and perhaps some on behalf of other organizations). The reason why farmers' cooperatives have emerged in the world, the main reason for this is that farmers need the services they provide. therefore, the purpose of cooperatives is to provide services to their members. from the perspective of the agricultural industrial chain, such services of cooperatives involve the agricultural infrastructure and the supply of goods for agricultural production before birth. Technical training, financing, information services, farming in production, irrigation and drainage, plant protection, technical guidance, pest control, harvesting, finance Services such as capital, post-natal transportation, storage, packaging, processing, marketing, financing, etc. The supply capacity of agricultural industrial chain services of farmers' cooperatives is affected by both internal and external factors. This paper focuses on the analysis of internal and external factors, and also considers the influence of the type of management products on the supply of cooperative services.

\subsection{Research Hypothesis}

\subsubsection{Internal factors and Service supply of Cooperative Agricultural Industry chain.}

1) The influence of leaders on the provision of cooperative services, whether in the context of the initial establishment of the system or in day-to-day management decisions, Huang Zuhui stressed the quality and level of key members (usually sponsors, leaders and major shareholders) of the Farmers' Professional Cooperation Organization. Even personality has an important impact on the establishment and development of cooperative organizations. Yuan Peng pointed out that entrepreneurial talents with cooperative spirit are the necessary conditions for the emergence of cooperative organizations. Guo Lulai thought that there would be no entrepreneurs without cooperatives. Cooperatives. Huang Feng and Yang Dan find entrepreneurs in charge of cooperatives to significantly influence the cooperative ability. Excellent lateral service entrepreneurship in the agricultural industry chain service supply cooperatives in the process of cooperative leaders may be better through rules, the use of business and scientific management methods to achieve the service supply cost and risk mitigation.
Lei Xinghu and others believe that entrepreneurs are the first driving force in economic development, and the size of the entrepreneurial impetus is positively related to whether or not they are motivated and the degree of motivation. Huang Shengzhong found the entrepreneurial talent of the lead person (chairman). The empirical results of Huang Zuhui and Gao She-ling also show that the positive incentive to the president will influence the realization of the service function of the farmer professional cooperative.

Therefore, this paper proposes hypothesis 1: leadership entrepreneurial talent and giving incentives to cooperative leaders have a significant positive impact on the service supply of cooperative agricultural industrial chain.

2) The influence of member size on the Service supply of Cooperatives the importance of member size to the Development of Cooperatives has been paid much attention by scholars. However, the influence of member size on the supply of Service to Cooperatives is not consistent with previous studies. For example, Huang Ji $\mathrm{B}$ and others conducted a simple grouping study on the size of their members and found that, the service function index of the organization with less than 25 people is 2.9, while that of the organization with more than 25 people is 3.2 , that is, the service function of the organization has a positive correlation with the size of the members at the beginning of the organization. The continuous expansion of the size of cooperative members and the negative supply of financing services to cooperatives the impact of these studies has become more pronounced. The possible reason for the inconsistency of these findings is that, on the one hand, compared to the number of small members, with the growing size of cooperative members and the increasing degree of internal integration, Its market availability and negotiating power will gradually increase, which will contribute to the reduction of service costs in the agricultural industrial chain; on the other hand, with the expansion of membership, the costs of decision-making, management and coordination within cooperatives will increase... in addition, The influence of member size on different service content may be different, because different service content, member size advantage is different. Therefore, membership size on cooperative agricultural industry chain service impact needs to be differentiated service content to revalidate.

Based on the above analysis, this paper puts forward the hypothesis 2: the impact of member size on the supply of prenatal, postpartum, postpartum and financing services is different.

3) The influence of Decision-making Mechanism on the supply of Cooperative Service Decision-making Mechanism has an important influence on the supply of Cooperative Service. On the one hand, the democratic decision-making mechanism of "one person, one vote" can better communicate the various service demands of members to the organization. It can also increase to a certain extent the participation of members in the day-today affairs of cooperatives. On the other hand, this absolute democratization, especially in core decisionmaking involving matters such as internal distribution of 
interests, Democratization may also enhance members' bargaining power over service providers, thereby depriving service providers of the opportunity to obtain "surplus" to a certain extent, which may be detrimental to the exertion of cooperative service functions. Zhang lotus and Feng Kaiwen, Cui Baoyu and Chen Jiang think that the current cooperative formation of decisionmaking pattern segmentation and capital control has the reality and necessity. Zuhui Huang also believes that at this stage will tend to seek and maintain the rights and interests of farmers from the point of view to study even to guide farmers' cooperative organization, is not conducive to the healthy development of the farmer cooperative organization.

Therefore, this paper puts forward hypothesis 3: the absolute democratic decision-making mechanism of one person, one vote is not conducive to the supply of service in cooperative agricultural industrial chain.

\subsection{2 external factors and service supply of cooperative agricultural industrial chain.}

1) The influence of external forces on the supply of cooperative services; the influence of external forces on the formation and development of cooperative economic organizations is also an empirical issue to some extent. Because the involvement of external forces helps to make up for the shortage in the supply of entrepreneurs in cooperative organizations. Zhao Xiaofeng believes that if farmers want to move towards cooperation, they cannot do without the strong involvement of state forces, and only the state can play its role at all levels. But on the other hand, the intervention of external forces may ignore the basic conditions necessary for the development of the organization, at the same time, it is also the most fundamental, and may lack the internal motive force of the development organization. Kong Xiangzhi and Shi Bingqing also believe that adopting a top-down approach can easily lead to the failure of organizations to perform their functions well, while endogenous cooperative economic organizations can truly fulfill the cooperative principle.

Based on this, this paper proposes hypothesis 4: whether there are external forces involved in cooperatives has no significant influence on the service supply of agricultural industrial chain.

2) The impact of market conditions on the supply of cooperative services in terms of the impact of market conditions on the development of cooperatives, empirical studies by Shi Minjun and others have shown that. The channel of farmers selling agricultural products has significant influence on farmers' intention to participate in cooperative organization. Guo Hongdong and Jiang Wenhua think that farmers' participation in cooperative organization is influenced by the degree of local market development and the level of economic development. The empirical study found that, the market conditions of the village have a certain influence on the improvement of the organizational service function. The better the market conditions of the members of the cooperative are located, the closer the farmers are to the agricultural products trading market, the more the farmers purchase and produce the agricultural resources the easier it is to sell, the less necessary the organization is to provide agricultural and product sales services, and vice versa.

Therefore, hypothesis 5 is put forward: the more favorable market conditions are, the more disadvantageous the supply of pre-natal and post-natal services in cooperatives is, but it has no significant effect on the supply of other services.

\subsection{3 types of operating products and service supply of cooperative agricultural industrial chain.}

The main products operated by cooperatives can be divided into grain, oil and general cash crops, vegetables and fruits, and livestock and poultry aquaculture. The characteristics of the products are the main reasons for the transaction costs of agricultural products and also affect the production of cooperatives. Important factors for development. There are significant differences in the technical characteristics of production and the market transaction characteristics of different agricultural products, such as grain, cotton, etc., which have the characteristics of storage and not easy to damage, while vegetables and fruits are perishable. Perennial trees such as fruit trees have a higher degree of asset specificity, but the most important aspects of livestock, poultry, aquatic products are raising, slaughtering, processing and other links require stronger site specificity Because of the difference of product characteristics, there are differences in organizational scale, governance structure and operation performance among cooperatives of different product types.

Based on the above analysis, this paper puts forward hypothesis 6: there are significant differences between grain, oil and general cash crops, vegetables and fruits, livestock and poultry aquaculture in prenatal, production, postpartum and financing service supply.

\section{RESEARCH PROOF}

\subsection{Investigate and Survey}

In order to analyze the service supply of cooperative agricultural industry chain in depth, the research group conducted a field investigation on farmers' professional cooperatives in Zhejiang Province in July and August 2015. Selected from Hangzhou, Jiaxing, Ningbo, Shaoxing, 176 cooperatives in 14 counties and cities in Jinhua and Lishui conducted field visits and questionnaires. All the questionnaires were filled out either by the investigators in a one-question and oneanswer manner or by the respondents themselves. The main contents of the questionnaire include the basic situation of cooperatives, internal governance, service for members, production and operation, operating performance and income distribution, the basic situation of the village or street, and so on. A total of 176 questionnaires were completed, all of which were valid. Excluding the main product types, 14 questionnaires were selected, and 162 questionnaires were selected, of 
which 49 were grain and general cash crop cooperatives. Accounting for $30.25 \%$ of the total number of cooperatives surveyed, 72 cooperatives for vegetables and fruits, 44.44kum, 41 cooperatives for livestock and poultry aquaculture.

From the perspective of the entire industrial chain, cooperative agricultural services include: prenatal services, in-production services, post-natal services, and, in addition, financing services may exist before, during and after childbirth. In particular, lending services are difficult to distinguish between prenatal, mid- and postpartum. Therefore, a separate list of types of financing services is presented here. It is worth noting that, in this study, as long as one of the types of services provided by a cooperative is involved, the cooperative is deemed to have provided that type of agricultural industrial chain service. See Table 1 for details on the supply of various types of services provided by cooperatives.

\subsection{Empirical analysis}

\subsubsection{Model selection}

Considering that different factors may have different effects on the supply of different types of services in cooperatives, four models are constructed to study the effects of each factor on the supply of pre-natal, postnatal, post-natal and financing services in cooperatives.

In the selection of dependent variables, this paper choose whether to provide prenatal services as a cooperative service model of influencing factors of the dependent variable, whether the production of services as a service in producing model variable, whether to provide services as a service model of postpartum postpartum dependent variable, whether to provide financing services as a financing service model of the dependent variable and set the following factors influence Logistic model to analyze the various types of service supply cooperatives:

$Y i, j=\alpha i, j+\beta 1 i, j G S i, j+\beta 2 i, j X Q i, j+\beta 3 i, j a g e i, j+\beta 4 i$, jedui, $\mathrm{j}+\beta 5 \mathrm{i}$, jnfai, $\mathrm{j}+\beta 6 \mathrm{i}$, jwagi, $\mathrm{j}+\beta 7 \mathrm{i}$, jnumi, $\mathrm{j}+\beta 8 \mathrm{i}$, jdeci, $j+\beta 9 i$, jpati, $j+\beta 10 i, j m a r i, j+\mu i, j(1)$,respectively denote the antenatal services of cooperatives and the inproduction services. Provision of Postpartum Services and financing Services indicates whether the $J$ cooperative provides class I services. GSinj indicates whether the $\mathrm{j}$ cooperative in the I category is a vegetable and fruit cooperative. A value of 1 that the $J$ cooperative in Class I services is a livestock and poultry aquaculture cooperative, it is a value of 1 , otherwise 0 ? The purpose of setting up the virtual variables of GSiJ and XQinj is to test hypothesis 5, that is, the comparison between vegetable and fruit cooperatives and livestock and poultry aquaculture cooperatives. Whether there are significant differences in the supply of various services between grain, oil and general cash crop cooperatives. In this study, the age of the leaders of the first cooperative in the category I services was indicated by the use of ageijieduij and nfaij, respectively. Education level and organizational management experience. [2] These three variables reflect the human capital status of cooperative leaders. But the supply of cooperative services will also enhance leaders' organizational management experience, a potential causal feedback relationship that could lead to endogenous problems. In this paper, predeterminate variables are used to measure the explanatory variables of possible endogenetic problems. The organizational management experience of the leaders is reflected by whether the cooperative leaders engaged in nonagricultural industries prior to joining the cooperatives. The older the leaders are, the more educated they are, the higher the human capital of previous non-agricultural industries. Thus, the more favorable the cooperative agricultural service supply. Wagij indicates whether the $\mathrm{j}$ leader of the cooperative receives wages from the cooperative in Class I services and sets them to virtual variables with values of 1 and 0 , which are mainly used to reflect the incentive to the leader. Expectation Leaders who receive wages or subsidies from cooperatives will be encouraged, thus, it has a positive effect on the supply of service in cooperative agricultural industrial chain. Numij indicates that there may be a causal feedback relationship between the size of the member and the supply of agricultural service in the cooperative, and the size of the member of the cooperative is the size of the member of the $\mathrm{j}$ of the cooperative in the category I service. Therefore, this paper uses the value of the number of cooperative members at the end of last year to express the size of the members. The expected size of members affects the supply of service in cooperative agricultural industrial chain is uncertain. The impact on different services may vary.

Decij indicates whether the mode of voting (decision-making) of the $\mathrm{j} / \mathrm{s}$ in category I services in matters of size and size is not one person, one vote, such as one share, one vote or one person, one vote combined with one share, one vote, one vote, Set to a virtual variable with values of 1 and 0 . It is expected that the decision-making mechanism, which is not one person, one vote, will have a positive impact on the supply of service in the cooperative agricultural industrial chain. Whether the service model is an "external organization (enterprise), Associations, etc.) Cooperatives (bases) farmers ", that is, whether there are any organizations other than cooperatives to intervene in cooperative services, set to value the expected impact of the involvement of external forces on the supply of cooperative agricultural services is uncertain. Marij indicates that the village or street where the cooperative is located in Class I services has a primary market for agricultural products, the virtual variables with values of 1 and 0 are set to reflect the market conditions of the cooperative location. It is expected that the primary market of agricultural products owned by the village or street of the cooperative will have a negative impact on the supply of post-natal service of the cooperative.

\subsection{2 results and analysis}

Table 3 shows the estimated results of the Logistic model for the factors affecting the supply of various kinds of services. From the results of the model estimation, the overall goodness of fit of the model is high, and most of the variables affect the supply of cooperative agricultural services in some way. The 
model can be used to analyze the influence factors of cooperative service supply.

1) The internal factors of the estimation results show that effects of age on cooperatives chairman of postpartum service supply is positive, and statistically significant at the $5 \%$ level. In other words, other factors at the same level, $\mathrm{CO}$ chairman of the older, the more abundant social experience, social capital is high, and thus more conducive to Cooperatives provide postpartum service, such as sales service. But the chairman of the age of the other three types of cooperative service supply is not significant. Table 3 shows the director of education of cooperatives prenatal, births, there has a positive impact of postpartum and financing service supply, consistent with the prediction effect, and in 5\%, $1 \%, 5 \%$ and the 5 percent level is significant. This shows that more educated directors have higher human capital. It has a positive effect on the development of cooperatives and the supply of various services. The non-agricultural experience of the director only has a positive impact on the supply of services in the production of cooperatives and is significant at the level of $1 \%$. However, its influence on the other three types of service supply has not passed the significance test. In particular, the director's educational level passes the significance test and the direction of influence is consistent with the influence expectation. As can be seen from table 3 , in the case of the same level of other factors, the chairman of the board of directors Cooperatives receiving wages or subsidies are more conducive to the provision of pre-natal, in-production and post-natal services than cooperatives where the chairman does not receive wages or subsidies. Both of them pass the significance test at the level of $1 \%$. The director who receives salary or subsidy can encourage the director to devote himself more enthusiastically to the service of his members. But the effect of this variable on the supply of financing services has not passed the significance test. This may be that financing services require more money and financial management than antenatal, mid- and postnatal services, which cannot simply be achieved by giving wages and subsidies. Hypothesis 1 is verified.

2) The size of members has a positive impact on the supply of post-natal and financing services to cooperatives, and they pass the significance test at the levels of $5 \%$ and $1 \%$ respectively. The positive effect on the supply of post-natal and financing services of cooperatives is stronger. However, the effect of member size on the supply of pre-natal and in-production services of cooperatives has not passed the significance test. The reason may be that the larger the size of members, the more the purchase of agricultural materials before birth. The more difficult it is to reach agreement on technical training, the more difficult it is to achieve technical guidance and disease prevention in production. But after delivery, transportation, storage, processing, packaging, and selling agricultural materials on credit, establishing internal mutual fund mechanisms, etc. Only when the scale is large can there be cost advantage. Hypothesis 2 is basically verified.

3 ) The variables that characterize the decisionmaking mechanism have not passed the significance test in the four models of influencing factors of cooperative service supply. In other words, for the cooperatives at the present stage of development, there is no significant difference between the absolute democratization mechanism and the combination of one person, one vote, one share, one vote, or one share, one vote and other non-democratic decision-making mechanisms on the service supply. Hypothesis 3 has not been verified.

4 ) According to Table 3, there is a significant positive influence on the postpartum service supply in the cooperative service mode. And at the level of 5\%, the significance test is passed. This shows that when there are outside enterprises or associations involved in cooperative services, it is advantageous for them to carry out postnatal services, such as postnatal sales, if a cooperative can sign a contract with an enterprise to purchase and sell, or if an organization, such as an association or federation, provides it with relevant sales information, it will obviously contribute to the provision of post-natal services to the cooperative. The supply of intermediate and financing services has not had a significant impact. It may be in cooperatives at the present stage of development, outside forces are most concerned about postnatal services, such as sales. There is not much attention paid to the purchase of prenatal agricultural materials, technical training, field management in production, credit sales of agricultural materials, and the establishment of internal mutual funds mechanisms. So, the effect is not significant. Hypothesis 4 has not been fully verified. The variables that characterize market conditions pass the significance test and the direction of influence is consistent with the influence expectation. That is, the primary market of agricultural products owned by the village or street in which the cooperative is located has a negative influence on the supply of pre-natal and post-natal services of the cooperative, which is significant at the levels of $5 \%$ and $1 \%$, respectively, but has no significant effect on the supply of intermediate and financing services. Hypothesis 5 is verified.

5) The supply of antenatal services in vegetable and fruit cooperatives is higher than that in grain, oil and general cash crop cooperatives, and has passed the significance test at a level of $10 \%$. There is no significant difference in the provision of post-natal and financing services. It may be that fruit tree cultivation requires more technical training than grain and oil crops. And the construction of vegetable shed also needs the cooperative to provide the service more. The financing service of the livestock and poultry aquaculture cooperative is higher than that of the grain, oil and general cash crop cooperative, and is significant at the level of 5\%. The provision of services during and after production is not significantly different from that of grain, oil and general cash crops the possible reason is that livestock and poultry aquaculture has strong site specificity and uncertainty in the trading of its products, which makes it need strong financial support. Hypothesis 6 is basically verified. 


\section{4 conclusion}

Based on the data of 162 farmers' cooperatives in 14 counties and cities in 6 cities of Zhejiang Province, this paper deals with the prenatal and middle production of cooperatives. The present situation of postnatal and financing service supply and its influencing factors are studied empirically. The following main conclusions are drawn: (1) most cooperatives provide antenatal and postnatal services to their members, followed by financing services. But less than half of cooperatives provide in-production services. (2) the human capital of cooperative leaders, in particular, the level of education significantly positively affects the supply of cooperative services and encouraging leaders can also be significantly beneficial to pre-natal cooperatives.[3] Size of members of cooperatives the bigger, the more favorable it is for cooperatives to provide postnatal and financing services external forces intervene in cooperatives to have a significant positive impact on the supply of postnatal services. favorable market conditions are not conducive to cooperative prenatal and postnatal services to supply no more than $6 \%$ of vegetables and fruits. The supply of antenatal services in cooperatives is higher than that in grain, oil and general cash crop cooperatives. The supply of financing services in livestock and poultry aquaculture cooperatives is higher than that in grain, oil and general cash crop cooperatives.

The conclusions of this paper have profound policy implications in the following aspects: first, we should pay attention to the promotion of cooperative leaders' human capital and encourage them, on the one hand, we can increase the management of cooperative leaders at present. Education and training in areas such as professional knowledge; on the other hand, consideration may be given to introducing managers with good vocational education, and it is also necessary to give certain material incentives to leaders. Second, it is necessary to encourage the association and cooperation among cooperatives. Enhanced service capacity, such as cooperatives with transport, processing and other facilities, can collaborate with similar cooperatives that do not have such facilities, using them as members of both sides Third, to explore and strengthen the support for the provision of post-natal and financing services by cooperatives, for example, Encourage and support financing institutions to increase cooperative credit quota. Fourth, encourage cooperatives and external market entities through order sales and other aspects of cooperation, support cooperatives to become bigger and stronger.

\section{ACKNOWLEDGMENT}

This work was supported by Doctor's Research Fund of Sichuan police college in China (646000), Research on the Influence of Farmer Specialized Cooperatives on Rural Revitalization (2018YJBSQD25).

\section{REFERENCES}

1. Samuel Burer, Philip C. Jones, Timothy J. Lowe. Coordinating the supply chain in the agricultural seed industry[J]. European Journal of Operational Research,2006,185(1).

2. Yong Xiangqi Nutlike Bergmann, Zhi-qiang WANG, Jian WANG. A Dairy Industry Information Cooperative Service System Based on a Production Process Ontology[J]. Journal of Integrative Agriculture,2012,11(5).

3. Bezuidenhout, Carel Nicolaas, Bodhanya, Shamim, Brenchley, Linda. An analysis of collaboration in a sugarcane production and processing supply chain[J]. British Food Journal,2012,114(6).

4. Jizya An, Lei Wang, Xiaohua Lv. Research on AgriFood Cold Chain Logistics Management System: Connotation, Structure and Operational Mechanism[J]. Journal of Service Science and Management,2015,08(06).

5. Global Agricultural and Farm Pump Industry 2016 Market Report; Launched via MarketResearchReports.com[J]. M2 Presswire,2016.

6. Zheng Wang, Guiping Lin. A new business model to Chinese style agricultural industrialization[J]. Emerald Emerging Markets Case Studies,2012,2(8).

7. Katrina Sinclair, Allan Curtis, Emily Mendham, Michael Mitchell. Can resilience thinking provide useful insights for those examining efforts to transform contemporary agriculture? [J]. Agriculture and Human Values, 2014,31(3).

8. Ping Shi, Bo Yan. Factors affecting RFID adoption in the agricultural product distribution industry: empirical evidence from China[J]. SpringerPlus,2016,5(1). 